\title{
AlGaN Quadruple-band Photodetectors
}

\author{
Mutlu Gökkavas ${ }^{1}$, Serkan Butun ${ }^{1}$, Piotr Caban ${ }^{2,3}$, Wlodek Strupinski ${ }^{2}$ and Ekmel Ozbay ${ }^{1}$ \\ ${ }^{1}$ Nanotechnology Research Center, Department of Physics, Department of Electrical and Electronics Engineering, \\ Bilkent University, Bilkent, Ankara 06800 Turkey \\ ${ }^{2}$ Institute of Electronic Materials Technology, Wolczynska 133,01-919 Warsaw, Poland \\ ${ }^{3}$ Institute of Microelectronics and Optoelectronics, Warsaw University of Technology, Koszykowa 75, 00-662 Warsaw, Poland
}

\begin{abstract}
Quadruple back-illuminated ultraviolet metalsemiconductor-metal photodetectors with four different spectral responsivity bands were demonstrated. The average of the fullwidth at half-maximum (FWHM) of the quantum efficiency peaks was $9.98 \mathrm{~nm}$.
\end{abstract}

\section{INTRODUCTION}

$\mathrm{Al}_{\mathrm{x}} \mathrm{Ga}_{1-\mathrm{x}} \mathrm{N}$ based photodetectors have emerged as an alternative to conventional ultraviolet (UV) sensors with the advent of metal organic chemical vapor deposition (MOCVD) systems [1]-[2]-[3]. Many workers have demonstrated metalsemiconductor-metal (MSM) [4]-[5], Schottky [6], p-i-n [7] and avalanche type [8] AlGaN UV photodetectors successfully. Ultraviolet detectors have a wide range of applications in flame, fire and missile detection, chemical and biological analysis, short distance non-line-of-sight optical communications, as well as emitter calibration. The existing fire warning systems utilize infrared (IR)/IR [9], UV/IR, or UV/visible/IR channels. Multiband narrow-spectrum UV detectors would in turn increase the fire source and range recognition capabilities of such systems and help to eliminate false alarms. One method of narrow spectral-band detection is to employ absorptive epitaxial filter-layers [10]. In the present paper, we report our work on quadruple-band UV MSM photodetectors that are fabricated on a single chip. Metalsemiconductor-metal type photodetectors are preferred since they simplify the growth and fabrication processes, exhibit very low dark currents [11], and allow for operation even in the deep UV [12].

\section{SAMPLE FABRICATION}

The investigated epitaxial sample incorporates nine $500 \mathrm{~nm}$ $\mathrm{Al}_{\mathrm{x}} \mathrm{Ga}_{1-\mathrm{x}} \mathrm{N}$ layers that were grown by MOCVD with decreasing $\mathrm{Al}$ concentration in each layer. Optical transmission tests revealed that the $\mathrm{Al}$ concentration of the layers varied from 0.50 to 0.08 from bottom to top of the structure. When illuminated from the substrate side, every layer acts as a high-wavelength pass spectral filter for the above layers with a lower $\mathrm{Al}$ concentration.

For the fabrication of the quadruple-band photodetectors, the sample surface was lithographically protected and etched during a series of reactive ion etching (RIE) steps. The respective four quadrants of the quadruple photodetector were recess-etched to the first (no etch), third, fifth and seventh layers prior to MSM finger metallization. The spacer layers between the actual photodetector layers were reserved as spectral filters. On the as-grown and three staircase-like etched quadrants of the quadruple photodetector area, MSM photodetectors were fabricated by the deposition of $100 \AA \mathrm{Pt} / 2000 \AA \mathrm{Au}$ finger metallization in a single step. The width and spacing of the interdigitated fingers were $3 \mu \mathrm{m}$, and the device active areas were $180 \mu \mathrm{m} \times 180 \mu \mathrm{m}$. A photomicrograph of the completed quadruple photodetector is shown in Fig. 1. The arrangement of one detector on each quadrant allows for the uniform illumination through a circularly symmetric light probe such as a fiber or a laser beam.

\section{RESULTS}

The fabricated devices exhibited good dark current characteristics below the level of $10^{-10} \mathrm{~A}$ in the $0-100 \mathrm{~V}$ range. The spectral responsivity of the devices was measured by using a Xe lamp and monochromator assembly. The quantum efficiency of all four devices is plotted in Fig. 2 for the $250 \mathrm{~nm}-375 \mathrm{~nm}$ spectral range. For an improved visualization of the spectral shape of the response, the quantum efficiency of each detector was normalized to the value at the respective peak wavelength. The exact value of the peak quantum efficiency was $0.25,0.47,0.14$ and 0.03 for the devices fabricated on quadrants 1, 2, 3 and 4, respectively. Similarly, the full-width-at-half-maximum (FWHM) of the quantum efficiency peak was $8.3 \mathrm{~nm}, 12.1 \mathrm{~nm}, 11.4 \mathrm{~nm}$, and $8.1 \mathrm{~nm}$, for the respective devices on quadrants $1,2,3$ and 4 . The wavelength separation at the half-maximum normalized quantum efficiency between the red edge of one peak and the blue edge of the next peak was $15 \mathrm{~nm}, 18 \mathrm{~nm}$, and $33 \mathrm{~nm}$ for the detector pairs 1-2, 2-3, and 3-4, respectively. The separation is a direct result of the existence of the additional absorptive filter layers sandwiched between the detector active layers. The blue edge of each detector response coincides with the cut-off wavelength of the filter layer beneath.

\section{CONCLUSIONS}

In conclusion, we designed, fabricated, and tested monolithic quadruple band UV MSM photodetectors on a multilayer AlGaN heterostructure. The sample structure consisted of nine discrete layers: four active device layers sandwiched between five spectral filter layers. The average of the FWHM of the quantum efficiency peaks was $9.98 \mathrm{~nm}$. This result demonstrates that it is possible to obtain the desired spectral position, FWHM, and peak-to-peak separation by the incorporation of filter layers and the optimization of the layer compositions and thicknesses in the epitaxial structure. 


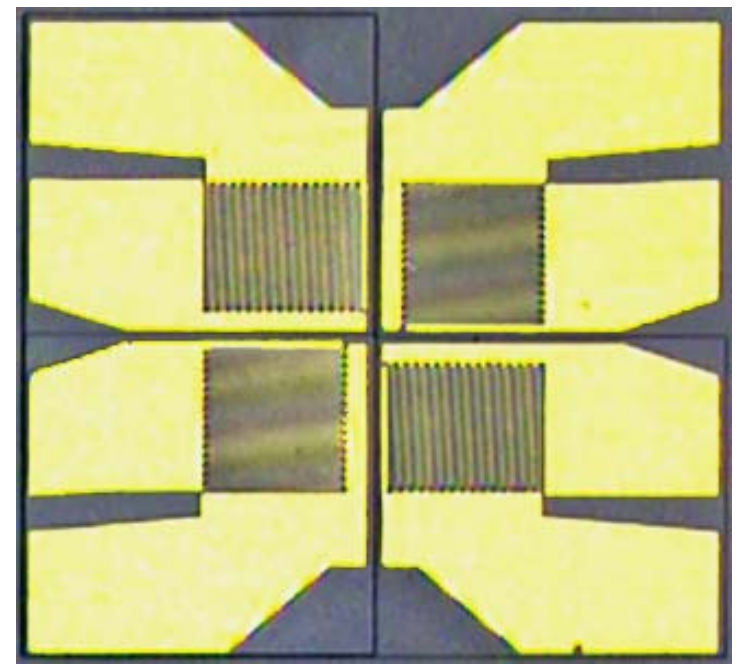

Fig. 1 Photomicrograph showing quadruple-band MSM photodetectors.

\section{ACKNOWLEDGMENT}

This work was supported by the European Union under the projects EU-PHOME and EU-ECONAM, and TUBITAK under the project numbers 105A005, 106E198, and 107A004. One of the authors (Ekmel Özbay) also acknowledges partial support from the Turkish Academy of Sciences.

\section{REFERENCES}

[1] M. Razeghi, and A. Rogalsky, "Semiconductor ultraviolet detectors," J. Appl. Phys., vol. 79, pp.7433-7473, 1996.

[2] E. Monroy, F. Omnes, and F. Calle, "Wide-bandgap semiconductor ultraviolet photodetectors," Semicond. Sci. Technol., vol. 18, pp. R33R51, 2003.

[3] M.A. Khan, M.Shatalov, H.P. Maruska, H.M. Wang, and E.Kuokstis, "III-nitride UV devices," Jpn. J. Appl. Phys. P1, vol. 44, pp. 71917206,2005

[4] E. Monroy, F. Calle, E. Munoz, and F. Omnes, "AlGaN metalsemiconductor-metal photodiodes," Appl. Phys. Lett., vol. 74, pp. 3401-3403, 1999.

[5] T. Li, D. J. H. Lambert, A. L. Beck, C. J. Collins, B. Yang, J. M. M Wong, U. Chowdhury, R.D. Dupuis, and J. C. Campbell, "Solar-blind AlxGa1-xN-based metal-semiconductor-metal ultraviolet photodetectors," Electron. Lett., vol. 36, pp. 1581-1583, 2000.

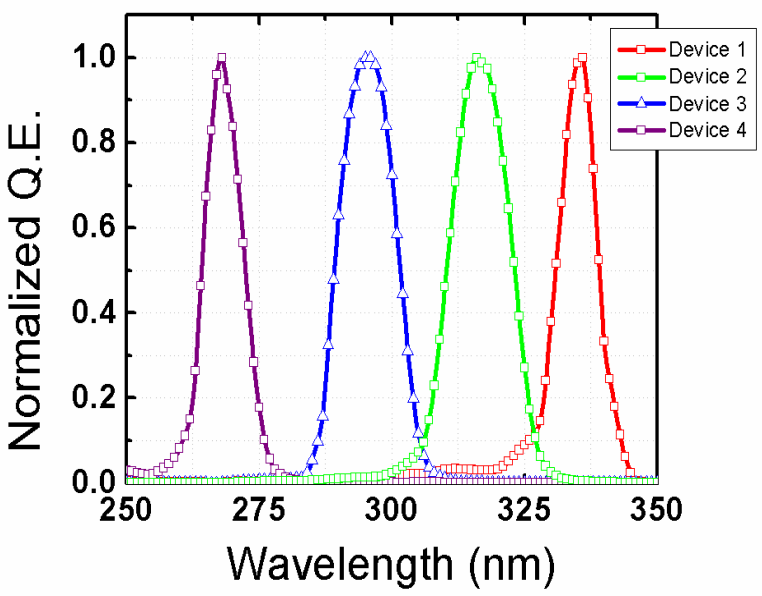

Fig. 2 Normalized quantum efficiency of quadruple-band photodetectors.

[6] N. Biyikli, T. Kartaloglu, O. Aytur, I. Kimukin, and E. Ozbay, "Highspeed visible-blind GaN-based indium-tin-oxide Schottky photodiodes," Appl. Phys. Lett., vol. 79, pp. 2838-2840, 2001.

[7] C. J. Collins, U. Chowdhury, M. M. Wong, B. Yang, A. L. Beck, R. D. Dupuis, and J. C. Campbell, "Improved solar-blind detectivity using an AlxGa1-xN heterojunction p-i-n photodiode,"Appl. Phys. Lett., vol. 80, pp. 3754-3756, 2002.

[8] T. Tut, B. Butun, M. Gökkavas, and E. Ozbay, "High performance $\mathrm{Al}(\mathrm{x}) \mathrm{Ga}(1-\mathrm{x}) \mathrm{N}-$ based avalanche photodiodes," Photonics and Nanostructures-Fundamentals and Applications, vol. 5, pp. 140-144, 2007.

[9] M.B. Reine, P.W. Norton, R. Starr, M.H. Weiler, M. Kestigian, B.L. Musicant, P. Mitra, T. Schimert, F.C. Case, I.B. Bhat, H. Ehsani, V. Rao, "Independently accessed back-to-back $\mathrm{HgCdTe}$ photodiodes - A new dual-band infrared detector," J. Electron. Mater., vol. 24, pp. 669679, 1995.

[10] M. Gökkavas, S. Butun, H.B. Yu, T. Tut, B. Butun, and E. Ozbay, "Dual-color ultraviolet metal-semiconductor-metal AlGaN photodetectors," App. Phys. Lett., vol. 89, 143503, 2006.

[11] S. Butun, M. Gökkavas, H.B. Yu, and E. Ozbay, "Low dark current metal-semiconductor-metal photodiodes based on semi-insulating GaN," App. Phys. Lett., vol. 89, 073503, 2006.

[12] S. Butun, T. Tut, M. Gökkavas, H.B. Yu, and E. Ozbay, "Deepultraviolet $\mathrm{A} 10.75 \mathrm{Ga} 0.25 \mathrm{~N}$ photodiodes with low cutoff wavelength," App. Phys. Lett., vol. 88, 123503, 2006. 